\title{
Efficacy and safety of icotinib as first-line therapy in patients with advanced non-small-cell lung cancer
}

This article was published in the following Dove Press journal:

OncoTargets and Therapy

24 February 2016

Number of times this article has been viewed

Yan-Wei Shen*
Xiao-Man Zhang*
Shu-Ting Li
Meng Lv
Jiao Yang
Fan Wang
Zhe-Ling Chen
Bi-Yuan Wang
Pan Li
Ling Chen
Jin Yang

Department of Medical Oncology, The First Affiliated Hospital of Xi'an Jiaotong University, Xi'an, Shaanxi, People's Republic of China

*These authors contributed equally to this work
Correspondence: Jin Yang Department of Medical Oncology, The First Affiliated Hospital of Xi'an Jiaotong University, No 277, Yanta West Road, Xi'an, Shaanxi 71006I, People's Republic of China

Tel/fax +86298532 3422

Email1473106133@qq.com
Background and objective: Several clinical trials have proven that icotinib hydrochloride, a novel epidermal growth factor receptor (EGFR)-tyrosine kinase inhibitor, exhibits encouraging efficacy and tolerability in patients with advanced non-small-cell lung cancer (NSCLC) who failed previous chemotherapy. This study was performed to assess the efficacy and toxicity of icotinib as first-line therapy for patients with advanced pulmonary adenocarcinoma with EGFR-sensitive mutation.

Patients and methods: Thirty-five patients with advanced NSCLC with EGFR-sensitive mutation who were sequentially admitted to the First Affiliated Hospital of Xi'an Jiaotong University from March 2012 to March 2014 were enrolled into our retrospective research. All patients were administered icotinib as first-line treatment. The tumor responses were evaluated using Response Evaluation Criteria in Solid Tumors (RECIST, version 1.1).

Results: Among the 35 patients, the tumor objective response rate (ORR) and disease control rate were $62.9 \%(22 / 35)$ and $88.6 \%(31 / 35)$, respectively. The median progression-free survival was 11.0 months (95\% confidence interval [CI]: 10.2-11.8 months), and median overall survival was 21.0 months (95\% CI: 20.1-21.9 months). The most common drug-related toxicities were rashes (eleven patients) and diarrhea (nine patients), but these were generally manageable and reversible.

Conclusion: Icotinib monotherapy is effective and tolerable as first-line treatment for patients with advanced lung adenocarcinoma with EGFR-sensitive mutation.

Keywords: lung neoplasms, icotinib hydrochloride, first-line treatment

\section{Introduction}

Lung cancer is the most commonly diagnosed cancer worldwide and also the most common cause of cancer-related mortality. ${ }^{1}$ The Chinese Cancer Registry Annual Report estimates that, based on statistics for 2011, the death rate from lung cancer in the People's Republic of China was 4.83/1,000,000, accounting for the major portion of all cancer-related deaths. ${ }^{2}$ Approximately $80 \%$ of all lung cancer cases are categorized as non-small-cell lung cancer (NSCLC), with lung adenocarcinoma being the most common pathological type. ${ }^{3}$ NSCLC is often diagnosed at an advanced stage and the prognosis is poor; it is estimated that the 5-year survival rate is $<15 \% .{ }^{4}$ For patients with NSCLC, cytotoxic chemotherapy treatments provide a modest survival advantage over best supportive care. However, the response rate of platinum-based regimens in advanced NSCLC is not $>40 \%$, and the therapeutic plateau has been reached with conventional chemotherapy. ${ }^{5}$ In addition, these agents are commonly associated with evident side effects, including myelosuppression, hepatotoxicity, nephrotoxicity, and neurotoxicity.

The treatment paradigm for patients with NSCLC is changing with the improved understanding of molecular signaling pathways. In recent years, epidermal growth 
factor receptor-tyrosine kinase inhibitors (EGFR-TKIs), such as erlotinib and gefitinib, represented the significant progress made toward treating NSCLC. Deletions in exon 19 and the L858R mutation in exon 21 are the most frequent EGFR-sensitive mutations, and these have been detected commonly in lung adenocarcinomas of Asian, female never-smokers. ${ }^{6}$ Several studies have reported that EGFR gene-activating mutations are strong molecular predictors of response to EGFR-TKIs in NSCLC..$^{7-9}$ Moreover, a series of latest clinical studies, including IPASS, NEJ002, WJTOG3405, OPTIMAL, EURTAC, LUXLUNG3, and LUXLUNG6, ${ }^{10-16}$ have shown that EGFR-TKIs as firstline therapy have more advantages than conventional cytotoxic chemotherapy in patients with advanced NSCLC, with significantly longer progression-free survival (PFS) (9.5-13.7 months vs 4.6-6.9 months) and higher objective response rate (ORR) (58\%-84\% vs $15 \%-47 \%$ ).

Icotinib is a novel, orally administered, reversible smallmolecule EGFR-TKI, designed and patented by Beta Pharma (Zhejiang, People's Republic of China). An in vitro study ${ }^{17}$ showed that icotinib could significantly inhibit the proliferation of human tumor cell lines (A431 cells) that overexpress EGFR. The antitumor effect of icotinib was similar to that of gefitinib in EGFR-mutated lung cancer cell lines (PC-9 and HCC 827$).{ }^{18}$ Data from animal experiments further confirmed that icotinib can strongly inhibit tumor growth in several xenograft models. ${ }^{19}$ Furthermore, the results of Phase I, I/IIa, and III clinical studies ${ }^{20-22}$ revealed that icotinib exhibited beneficial clinical antitumor activities and favorable tolerability in patients with advanced NSCLC. The ICOGEN trial ${ }^{22}$ was the first prospective head-to-head Phase III trial of EGFRTKIs, which was implemented to compare the efficacy and safety of icotinib versus gefitinib in patients with NSCLC after one or two failed treatments of chemotherapy. The trial revealed that icotinib demonstrated equivalent efficacy, better safety, and better tolerability relative to gefitinib in patients with NSCLC previously treated with chemotherapy.

Taking into consideration the encouraging results of ICOGEN, icotinib was approved by the State Food and Drug Administration of the People's Republic of China in August 2011 for the second- or third-line treatment of advanced NSCLC. In addition, considering that icotinib has a molecular structure similar to that of gefitinib and erlotinib, apart from being more cost-effective than gefitinib or erlotinib in the People's Republic of China, icotinib is also an alternative choice to treat patients with advanced NSCLC as a firstline treatment. ${ }^{23}$ A previous retrospective study ${ }^{24}$ analyzed
56 patients with advanced NSCLC using icotinib as the first-line treatment and reported that the ORR was $46.4 \%$, the disease control rate (DCR) was $78.6 \%$. In this retrospective analysis, however, only 18 cases had EGFR mutations. Thus, the results were not representative due to the existence of heterogeneous population and questions remained about the efficacy and safety of icotinib in patients with lung adenocarcinoma with EGFR-sensitive mutations. Here, we performed a retrospective study to evaluate the efficacy and tolerability of icotinib as first-line therapy in patients with advanced lung adenocarcinoma with EGFR-sensitive mutation.

\section{Patients and methods}

Patient eligibility

The study was approved by the institutional ethics committees of the First Affiliated Hospital of Xi' an Jiaotong University and written informed consent was obtained from each patient. We retrospectively analyzed the clinical data of patients with advanced lung adenocarcinoma and with EGFR-sensitive mutation between March 2012 and March 2014, who were treated with icotinib as the first-line treatment. The inclusion criteria for this study were as follows: 1) all cases histologically or cytologically validated; 2) patients with advanced or metastatic (stage IIIB or IV) lung adenocarcinoma and EGFR-sensitive mutation who had not received chemotherapy treatments before icotinib administration; 3) at least one measurable lesion according to the Response Evaluation Criteria in Solid Tumors 1.1 (RECIST, version 1.1); ${ }^{25}$ 4) Eastern Cooperative Oncology Group performance status (ECOG-PS) ${ }^{26}$ score $\leq 3$; and 5) no radiotherapy or interventional therapy and no other EGFR-TKI treatment administered concurrently with icotinib therapy. Patients were excluded if they had received any other EGFR inhibitors and if they had serious or severe hypersensitivity reactions to icotinib. Other exclusion criteria included uncontrolled central nervous system metastases or spinal cord compression, severe underlying cardiopulmonary diseases, a history of interstitial lung disease, and severe gastrointestinal disorders influencing drug absorption.

\section{EGFR gene mutation detection}

EGFR mutation detection was performed using the Scorpion amplification refractory mutation system (ARMS) kit manual from the manufacturing company (Qiagen, Venlo, the Netherlands). In this study, deletions in exon 19 and the L858R point mutation in exon 21 were considered sensitive mutations. 


\section{Treatment and response evaluation}

Icotinib hydrochloride was given orally at a dose of $125 \mathrm{mg}$ three times daily until disease progression or intolerable toxicity. No other systematic anticancer treatment was administered concurrently with icotinib treatment. Baseline evaluation of all patients was completed within 1 week before treatment. The assessment included complete medical history and physical examination, laboratory tests, electrocardiography, thorax computed tomography (CT) scan, enhanced magnetic resonance imaging of the skull, and examination of critical organs such as the liver and bone. Therapeutic evaluations were performed according to the RECIST criteria (version 1.1) and included complete response (CR), partial response (PR), stable disease (SD), and progressive disease (PD). The ORR comprises CR and $\mathrm{PR}$. The DCR was defined as $\mathrm{CR}, \mathrm{PR}$, and $\mathrm{SD}$. The radiological evaluation was performed by two independent oncologists. Generally, the first evaluation was performed at 1 month after starting icotinib, and then assessment was conducted every 2 months or at progression of an original symptom. Adverse events were graded according to the National Cancer Institute toxicity classification standard version $3.0 .^{27}$

\section{Follow-up}

All patients were evaluated for tumor response, PFS, and overall survival (OS). The final follow-up date was October 2, 2015. PFS was defined as the period from the first day of icotinib therapy to documented progression or death from any cause (calculated according to the event that occurred first). OS was for the span between the start of icotinib and the date of death or the final outpatient follow-up visit. Clinical data and outcomes were obtained by a search of patient medical records, consultation with the doctors in charge, and interviews in the outpatient clinic.

\section{Statistical analysis}

Descriptive statistics, including frequency and percentage, were used to summarize the study data. The chi-square test or Fisher's exact test (when there are expected frequencies less than five) was used to compare the differences in ORR and DCR after stratification by sex, age, smoking status, ECOG-PS, clinical staging, and EGFR mutation type. The median PFS and OS were calculated using the Kaplan-Meier, and the differences among the levels of possible prognostic factors were tested by the log-rank test in univariate analyses. A value of $P<0.05$ was considered statistically significant. Statistical analyses were conducted using SPSS 18.0 (SPSS Inc, Chicago, IL, USA).

\section{Results Baseline characteristics}

Between March 2012 and March 2014, a total of 119 patients with advanced lung adenocarcinoma were registered in our electronic medical records. According to the inclusion criteria, 35 consecutive patients with EGFR-sensitive mutation were included in this retrospective study. The whole cohort of patients included 19 (54.3\%) females and $16(45.7 \%)$ males. The age of the patients ranged from 42 years to 84 years, with a median age of 63 years. Among the 35 patients, 23 patients $(65.7 \%)$ were younger than 70 years of age, while $26(74.3 \%)$ were never-smokers, and nine $(25.7 \%)$ were current or former smokers. Most patients had an ECOG-PS of zero or one, and only 13 (37.1\%) patients had an ECOG-PS of two or three. According to the National Comprehensive Cancer Network Guidelines version 1.2015 for staging NSCLC, three (8.6\%) patients were at stage IIIB and 32 (91.4\%) had stage IV disease at study entry. Deletions in exon 19 were found in $21(60.0 \%)$ patients, while L858R point mutation in exon 21 was found in the remaining cases (Table 1).

\section{Response to treatment}

All 35 patients were evaluable for curative efficacy. The ORR was $62.9 \%$ (22/35, zero cases of CR, 22 cases of PR). Additionally, nine patients had SD, yielding an overall DCR of $88.6 \%$. Three out of seven patients exhibiting brain metastasis who received icotinib treatment after whole-brain radiation therapy achieved PR (Figure 1) and one patient exhibited SD. Female patients, never-smokers, patients younger than 70 years, and patients with ECOG-PS of zero or one had numerically superior ORR and DCR; however, the difference was not statistically significant. Moreover, there was also no significant difference in ORR and DCR between subgroups stratified by tumor, node, metastases (TNM) staging system or EGFR mutation type (Table 1).

\section{Disease-related symptom improvement}

Most of the patients (31 cases) exhibited a range of disease-related symptoms before treatment initiation. Twenty (64.5\%) out of 31 symptomatic patients underwent an obvious symptomatic improvement after icotinib treatment, especially for symptoms of cough, sputum, chest pain, and wheezes. In addition, three patients became completely asymptomatic. The mean time from first drug administration to symptomatic improvement was $\sim 3$ weeks. 
Table I Baseline demographic and clinical data of the study patients and therapeutic evaluation

\begin{tabular}{|c|c|c|c|c|c|}
\hline \multirow{2}{*}{$\begin{array}{l}\text { Clinical } \\
\text { characteristics }\end{array}$} & \multirow[t]{2}{*}{ n (\%) } & \multicolumn{2}{|l|}{ ORR } & \multicolumn{2}{|l|}{ DCR } \\
\hline & & n (\%) & $P$-values & n (\%) & $P$-values \\
\hline Total & 35 & $22(62.9)$ & - & $31(88.6)$ & - \\
\hline \multicolumn{6}{|l|}{ Sex } \\
\hline Female & $19(54.3)$ & $12(63.2)$ & 1.000 & $16(84.2)$ & 0.608 \\
\hline Male & $16(45.7)$ & $10(62.5)$ & & $15(93.8)$ & \\
\hline \multicolumn{6}{|l|}{ Age at diagnosis } \\
\hline$<70$ years & $23(65.7)$ & $15(65.2)$ & 0.726 & $22(95.7)$ & 0.106 \\
\hline$\geq 70$ years & $12(34.3)$ & $7(58.3)$ & & $9(75)$ & \\
\hline \multicolumn{6}{|l|}{ Smoking status } \\
\hline Never-smoker & $26(74.3)$ & $17(65.4)$ & 0.698 & $24(92.3)$ & 0.268 \\
\hline Current or former smoker & $9(25.7)$ & $5(55.6)$ & & $7(77.8)$ & \\
\hline \multicolumn{6}{|l|}{ ECOG-PS } \\
\hline 0 or 1 & $22(62.9)$ & $15(68.2)$ & 0.480 & $20(90.9)$ & 0.618 \\
\hline 2 or 3 & $13(37.1)$ & $7(53.8)$ & & II (84.6) & \\
\hline \multicolumn{6}{|l|}{ TNM staging system } \\
\hline IIIB & $3(8.6)$ & I (33.3) & 0.541 & $2(66.7)$ & 0.313 \\
\hline IV & $32(91.4)$ & $21(65.6)$ & & $29(90.6)$ & \\
\hline \multicolumn{6}{|l|}{ EGFR mutation type } \\
\hline Del 19 & $21(60.0)$ & $14(66.7)$ & 0.724 & I8 (85.7) & 0.635 \\
\hline L858R & $14(40.0)$ & $8(57.1)$ & & $13(92.9)$ & \\
\hline
\end{tabular}

Abbreviations: DCR, disease control rate; ECOG-PS, Eastern Cooperative Oncology Group performance status; EGFR, epidermal growth factor receptor; ORR, objective response rate; TNM, tumor, node, metastases.

\section{Survival analysis}

The median follow-up time was 24.3 months. At the end of follow-up (October 2, 2015), 22 patients died, 13 patients were still alive, and 12 patients were still on icotinib treatment. Median PFS for the 35 patients was 11.0 months (95\% confidence interval [CI]: 10.2-11.8 months) (Figure 2A), and median OS was 21.0 months (95\% CI: 20.1-21.9 months) (Figure 2B). On univariate analysis, the survival (both PFS and OS) was not found to be affected by sex, age at diagnosis, smoking history, ECOG-PS, stage of disease, or EGFR mutation type (Table 2).

\section{Icotinib-related toxicities}

At least one therapy-associated adverse event was registered in $26(74.3 \%)$ patients, of which 25 were mild and reversible. The most common toxicities were skin-related events
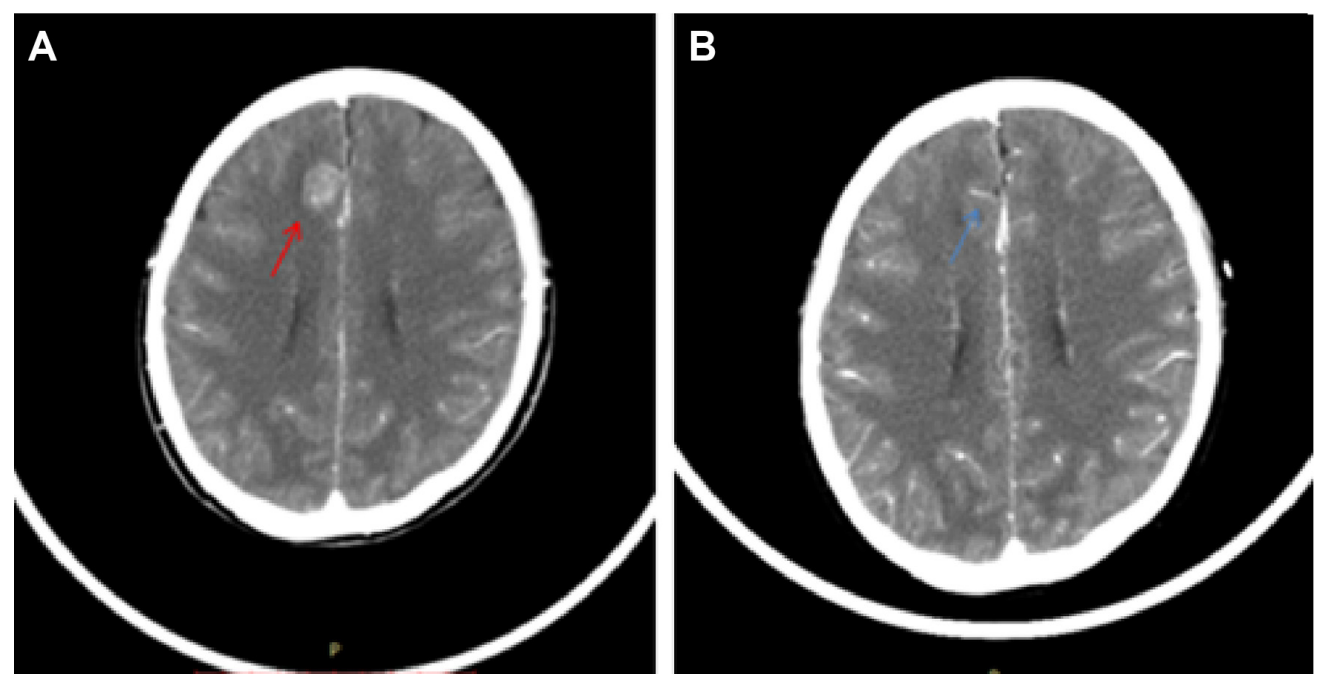

Figure I Imaging changes.

Notes: (A) Pre- and (B) posttreatment micrographs of cranium CT scan for a typical 47-year-old female patient with a favorable treatment outcome of cerebral metastases: compared with the baseline (red arrow), the metastasis focus was obviously shrunken after 3 months of icotinib treatment (blue arrow).

Abbreviation: CT, computed tomography. 


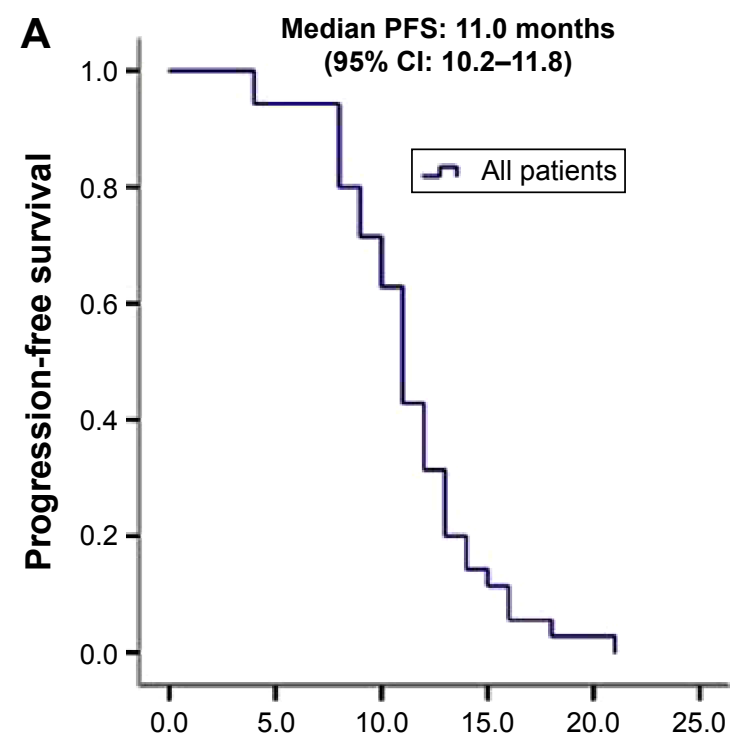

Months after treatment initiation

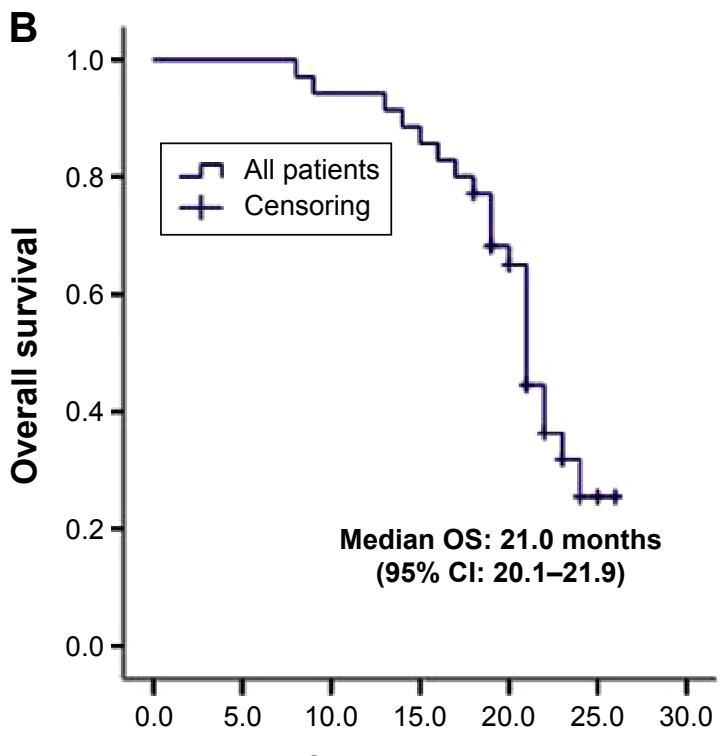

Months after treatment initiation

Figure 2 Kaplan-Meier survival curves of 35 patients with advanced lung adenocarcinoma with EGFR-sensitive mutation.

Note: (A) The PFS in all patients, (B) the OS in all patients.

Abbreviations: $\mathrm{Cl}$, confidence interval; EGFR, epidermal growth factor receptor; OS, overall survival; PFS, progression-free survival.

and diarrhea. Acne-like rash and diarrhea were observed in eleven (31.4\%) and nine (25.7\%) cases, respectively. Other common adverse events include dry skin, mucositis, nausea, asthenia, and elevated levels of aspartate transaminase and alanine transaminase. However, except for one case of grade III rash and one case of grade III diarrhea, all adverse events were of grades I or II. They were also transient and could be controlled with symptomatic therapy without the need for dose reduction or interruption of icotinib therapy. No possible drug-related interstitial pneumonia and drugrelated death occurred during treatment. The data are shown in Table 3.

\section{Discussion}

The EGFR-signaling pathway is closely involved in several key drivers of malignancy, including tumor cell proliferation

Table 2 Univariate survival analysis according to the patient characteristics (months)

\begin{tabular}{|c|c|c|c|c|}
\hline \multirow{2}{*}{$\begin{array}{l}\text { Clinical } \\
\text { characteristics }\end{array}$} & \multicolumn{2}{|l|}{ PFS } & \multicolumn{2}{|l|}{ OS } \\
\hline & Median (95\% Cl) & $\overline{\text { Log-rank } P \text {-values }}$ & Median (95\% Cl) & $\overline{\text { Log-rank } P \text {-values }}$ \\
\hline Total & $11.0(10.2-11.8)$ & - & $21.0(20.1-21.9)$ & - \\
\hline \multicolumn{5}{|l|}{ Sex } \\
\hline Female & $11.0(9.7-12.3)$ & 0.524 & $21.0(20.3-21.7)$ & 0.833 \\
\hline Male & $11.0(9.9-12.1)$ & & $17.0(\mid 5.6-26.3)$ & \\
\hline \multicolumn{5}{|l|}{ Age at diagnosis } \\
\hline$<70$ years & $12.0(10.2-13.8)$ & 0.293 & $21.0(19.4-22.6)$ & 0.356 \\
\hline$\geq 70$ years & $11.0(\mid 0.4-11.6)$ & & $21.0(18.0-24.0)$ & \\
\hline \multicolumn{5}{|l|}{ Smoking status } \\
\hline Never-smoker & $11.0(|0.2-1| .8)$ & 0.353 & $21.0(20.1-21.9)$ & 0.528 \\
\hline Current or former smoker & $11.0(5.2-16.8)$ & & $22.0(\mid 8.2-25.8)$ & \\
\hline \multicolumn{5}{|l|}{ ECOG-PS } \\
\hline 0 or 1 & $11.0(10.1-11.9)$ & 0.493 & $21.0(18.9-23.1)$ & 0.866 \\
\hline 2 or 3 & $11.0(9.2-12.8)$ & & $21.0(19.5-22.4)$ & \\
\hline \multicolumn{5}{|l|}{ TNM staging system } \\
\hline IIIB & Not reached & 0.570 & Not reached & 0.369 \\
\hline IV & $11.0(10.2-11.8)$ & & $21.0(20.2-21.8)$ & \\
\hline \multicolumn{5}{|l|}{ EGFR mutation type } \\
\hline Del 19 & $11.0(9.9-12.1)$ & 0.145 & $21.0(20.0-22.0)$ & 0.485 \\
\hline L858R & $11.0(9.2-12.8)$ & & $22.0(20.6-23.4)$ & \\
\hline
\end{tabular}

Abbreviations: $\mathrm{Cl}$, confidence interval; ECOG-PS, Eastern Cooperative Oncology Group performance status; EGFR, epidermal growth factor receptor; OS, overall survival; PFS, progression-free survival; TNM, tumor, node, metastases. 
Table 3 Summary of the nonhematologic adverse events

\begin{tabular}{llllll}
\hline $\begin{array}{l}\text { Adverse } \\
\text { effect }\end{array}$ & \multicolumn{2}{l}{ Toxic effect classification } & Patients, \\
\cline { 2 - 5 } & Grade I & Grade II & Grade III & Grade IV & n (\%) \\
\hline Skin rash & 8 & 2 & I & 0 & II (3I.4) \\
Dry skin & 4 & 0 & 0 & 0 & $4(I I .4)$ \\
Oral ulcer & 3 & 0 & 0 & 0 & $3(8.6)$ \\
Diarrhea & 5 & 3 & $\mathrm{I}$ & 0 & $9(25.7)$ \\
Nausea & 4 & $\mathrm{I}$ & 0 & 0 & $5(14.3)$ \\
Fatigue & 3 & $\mathrm{I}$ & 0 & 0 & $4(1 \mathrm{I} .4)$ \\
Elevated & $\mathrm{I}$ & $\mathrm{I}$ & 0 & 0 & $2(5.7)$ \\
AST/ALT & & & & & \\
\hline
\end{tabular}

Abbreviations: AST, aspartate transaminase; ALT, alanine transaminase.

and apoptosis, angiogenesis, invasion, and metastasis. ${ }^{28}$ The EGFR is often overexpressed in NSCLC and is a major target for new therapies. ${ }^{29}$ Specific EGFR-TKIs have been developed and used for targeted therapy of advanced NSCLC. Gefitinib and erlotinib, reversible EGFR-TKIs, yield prolonged survival and improved quality of life for patients with EGFR mutations with advanced lung adenocarcinoma when compared to the results of chemotherapy. ${ }^{30}$

Icotinib, a novel EGFR-TKI with completely independent intellectual property rights in the People's Republic of China, first exhibited equivalent response rates and superior safety and tolerability, when compared with gefitinib in a randomized, double-blind, multicenter, controlled, head-tohead trial (ICOGEN) ${ }^{22}$ on patients with advanced NSCLC previously treated in the People's Republic of China. The results indicated that icotinib showed equivalent ORR $(27.6 \%$ vs $27.2 \%$ ), DCR (75.4\% vs $74.9 \%$ ), and OS (13.3 months vs 13.9 months) compared with gefitinib. Additionally, icotinib showed median PFS extension of 1.2 months compared to gefitinib (4.6 months vs 3.4 months; $P=0.13$; hazard ratio: 0.84 ; 95\% CI: $0.67-1.05$ months), reaching the primary objective of noninferiority. With regard to safety, the overall adverse event rate was significantly lower in the icotinibtreated group compared with the gefitinib-treated group.

However, there has been insufficient evidence for its use as a first-line treatment. In the previous retrospective series, the EGFR mutation detection rates were relatively low. ${ }^{24,31,32}$ To the best of our knowledge, this is the first study to retrospectively analyze the efficacy and tolerability of icotinib as first-line therapy for patients with NSCLC with EGFR-sensitive mutation. This retrospective study of a novel EGFR-TKI, icotinib, in patients with advanced lung adenocarcinoma with EGFR-sensitive mutation showed an encouraging ORR (62.9\%) and DCR (88.6\%). The ORR of icotinib was similar to the efficacy of gefitinib and erlotinib in previous trials: the ORR was $83 \%$ in the OPTIMAL study, ${ }^{13}$
$71 \%$ in the EURTAC and the IPASS studies, ${ }^{10,14} 62 \%$ in the WJTOG3405 study, ${ }^{12}$ and 74\% in the NEJ002 study. ${ }^{11}$ In addition to its effects on the targeted lesion, icotinib hydrochloride can significantly improve systematic symptoms, including cough, pain, chest distress, dyspnea, and ECOG-PS. Hence, the patients' quality of life was improved.

Due to the short launching time of icotinib, long-term survival data have not yet been obtained in our study. The median PFS and OS were 11.0 months (95\% CI: $10.2-11.8$ months) and 21.0 months (95\% CI: 20.1-21.9 months), respectively, for all patients. All patients experienced good tolerance, with related adverse events mainly involving rash (eleven patients) and diarrhea (nine patients). None of the patients required therapy withdrawal due to adverse effects. Our findings were similar to data reported by the ICOGEN study, with the incidence of icotinib-related rashes being 39.5\% and that of diarrhea being $18.5 \%$. Therefore, the results of our study demonstrated that first-line icotinib treatment is a promising treatment choice for Chinese patients with advanced lung adenocarcinoma with EGFR-sensitive mutation.

Nevertheless, we observed no significant difference in tumor response rate and survival between subgroups of sex, age at diagnosis, smoking history, ECOG-PS, stage of disease, or EGFR mutation type. We consider that the main reason might be the relatively small number of cases included in our study. Interestingly, we show that icotinib hydrochloride provides a potentially therapeutic effect for patients with NSCLC with brain metastasis. The significant symptom relief observed in patients with brain metastasis indicated that icotinib can be delivered effectively across the blood-brain barrier into the brain.

One should note that there are certain limitations in our study. First, considering that our study was a retrospective analysis and all of the subjects were Chinese individuals, the results should be interpreted with caution, especially when interpreting improvement in disease-related symptoms and toxicity. The results need to be confirmed in larger and ethnically divergent population samples. Second, due to the short follow-up time, the potential long-term survival benefits of icotinib need to be addressed in future studies.

\section{Conclusion}

The results of this study illustrate that icotinib hydrochloride is effective and tolerable as first-line treatment for patients with advanced lung adenocarcinoma with EGFR-sensitive mutation. Further and more extensive research of icotinib in properly conducted trials with larger patient samples and other ethnic groups is warranted. 


\section{Acknowledgment}

The authors thank the patients and family members for their participation in this study.

\section{Disclosure}

The authors report no conflicts of interest in this work.

\section{References}

1. Jemal A, Siegel R, Xu J, Ward E. Cancer statistics, 2010. CA Cancer J Clin. 2010;60(5):277-300.

2. Chen W, Zheng R, Zeng H, Zhang S, He J. Annual report on status of cancer in China, 2011. Chin J Cancer Res. 2015;27(1):2-12.

3. Jemal A, Bray F, Center MM, Ferlay J, Ward E, Forman D. Global cancer statistics. CA Cancer J Clin. 2011;61(2):69-90.

4. Friedel G, Steger V, Kyriss T, Zoller J, Toomes H. Prognosis in N2 NSCLC. Lung Cancer. 2004;45(suppl 2):S45-S53.

5. Gridelli C, Rossi A, Maione P. Treatment of non-small-cell lung cancer: state of the art and development of new biologic agents. Oncogene. 2003;22(42):6629-6638

6. Mitsudomi T, Kosaka T, Yatabe Y. Biological and clinical implications of EGFR mutations in lung cancer. Int J Clin Oncol. 2006;11(3) 190-198.

7. Paez JG, Janne PA, Lee JC, et al. EGFR mutations in lung cancer: correlation with clinical response to gefitinib therapy. Science 2004;304(5676):1497-1500.

8. Lynch TJ, Bell DW, Sordella R, et al. Activating mutations in the epidermal growth factor receptor underlying responsiveness of non-small-cell lung cancer to gefitinib. $N$ Engl J Med. 2004;350(21):2129-2139.

9. Pao W, Girard N. New driver mutations in non-small-cell lung cancer. Lancet Oncol. 2011;12(2):175-180.

10. Mok TS, Wu YL, Thongprasert S, et al. Gefitinib or carboplatinpaclitaxel in pulmonary adenocarcinoma. $N$ Engl J Med. 2009; 361(10):947-957.

11. Maemondo M, Inoue A, Kobayashi K, et al. Gefitinib or chemotherapy for non-small-cell lung cancer with mutated EGFR. N Engl J Med. 2010; 362(25):2380-2388.

12. Mitsudomi T, Morita S, Yatabe Y, et al. Gefitinib versus cisplatin plus docetaxel in patients with non-small-cell lung cancer harbouring mutations of the epidermal growth factor receptor (WJTOG3405): an open label, randomised phase 3 trial. Lancet Oncol. 2010;11(2):121-128.

13. Zhou C, Wu YL, Chen G, et al. Erlotinib versus chemotherapy as first-line treatment for patients with advanced EGFR mutation-positive non-small-cell lung cancer (OPTIMAL, CTONG-0802): a multicentre, open-label, randomised, phase 3 study. Lancet Oncol. 2011;12(8): 735-742.

14. Rosell R, Carcereny E, Gervais R, et al. Erlotinib versus standard chemotherapy as first-line treatment for European patients with advanced EGFR mutation-positive non-small-cell lung cancer (EURTAC): a multicentre, open-label, randomised phase 3 trial. Lancet Oncol. 2012; 13(3):239-246.

15. Sequist LV, Yang JC, Yamamoto N, et al. Phase III study of afatinib or cisplatin plus pemetrexed in patients with metastatic lung adenocarcinoma with EGFR mutations. J Clin Oncol. 2013;31(27):3327-3334.
16. Wu YL, Zhou C, Hu CP, et al. Afatinib versus cisplatin plus gemcitabine for first-line treatment of Asian patients with advanced non-small-cell lung cancer harbouring EGFR mutations (LUX-lung 6): an open-label, randomised phase 3 trial. Lancet Oncol. 2014;15(2):213-222.

17. Gao Z, Chen W, Zhang X, et al. Icotinib, a potent and specific EGFR tyrosine kinase inhibitor, inhibits growth of squamous cell carcinoma cell line A431 through negatively regulating AKT signaling. Biomed Pharmacother. 2013;67(5):351-356.

18. Yang G, Yao Y, Zhou J, Zhao Q. Effects of icotinib, a novel epidermal growth factor receptor tyrosine kinase inhibitor, in EGFR-mutated non-small cell lung cancer. Oncol Rep. 2012;27(6):2066-2072.

19. Tan F, Shen X, Wang D, et al. Icotinib (BPI-2009H), a novel EGFR tyrosine kinase inhibitor, displays potent efficacy in preclinical studies. Lung Cancer. 2012;76(2):177-182.

20. Wang HP, Zhang L, Wang YX, et al. Phase I trial of icotinib, a novel epidermal growth factor receptor tyrosine kinase inhibitor, in Chinese patients with non-small cell lung cancer. Chin Med J. 2011;124(13): 1933.

21. Zhao Q, Shentu J, Xu N, et al. Phase I study of icotinib hydrochloride (BPI-2009H), an oral EGFR tyrosine kinase inhibitor, in patients with advanced NSCLC and other solid tumors. Lung Cancer. 2011;73(2): 195-202.

22. Shi Y, Zhang L, Liu X, et al. Icotinib versus gefitinib in previously treated advanced non-small-cell lung cancer (ICOGEN): a randomised, double-blind phase 3 non-inferiority trial. Lancet Oncol. 2013; 14(10):953-961.

23. Mao Y, Wu S. Treatment and survival analyses of completely resected thymic carcinoma patients. Onco Targets Ther. 2015;8:2503-2507.

24. Yang X, Zhang H, Qin N, et al. [Clinical observation of icotinib hydrochloride in first-line therapy for pulmonary adenocarcinoma]. Zhongguo Fei Ai Za Zhi. 2013;16(7):364-368.

25. Eisenhauer EA, Therasse P, Bogaerts J, et al. New response evaluation criteria in solid tumours: revised RECIST guideline (version 1.1). Eur J Cancer. 2009;45(2):228-247.

26. Oken MM, Creech RH, Tormey DC, et al. Toxicity and response criteria of the Eastern Cooperative Oncology Group. Am J Clin Oncol. 1982;5(6):649-655.

27. Trotti A, Colevas AD, Setser A, et al. CTCAE v3.0: development of a comprehensive grading system for the adverse effects of cancer treatment. Semin Radiat Oncol. 2003;13(3):176-181.

28. Normanno N, Bianco C, De Luca A, Maiello MR, Salomon DS. Targetbased agents against ErbB receptors and their ligands: a novel approach to cancer treatment. Endocr Relat Cancer. 2003;10(1):1-21.

29. Salomon DS, Brandt R, Ciardiello F, Normanno N. Epidermal growth factor-related peptides and their receptors in human malignancies. Crit Rev Oncol Hematol. 1995;19(3):183-232.

30. Lee YJ, Park IK, Park MS, et al. Activating mutations within the EGFR kinase domain: a molecular predictor of disease-free survival in resected pulmonary adenocarcinoma. J Cancer Res Clin Oncol. 2009;135(12) $1647-1654$.

31. Gu A, Shi C, Xiong L, Chu T, Pei J, Han B. Efficacy and safety evaluation of icotinib in patients with advanced non-small cell lung cancer Chin J Cancer Res. 2013;25(1):90-94.

32. Chen X, Zhu Q, Liu Y, et al. Icotinib is an active treatment of non-smallcell lung cancer: a retrospective study. PLoS One. 2014;9(5):e95897.
OncoTargets and Therapy

\section{Publish your work in this journal}

OncoTargets and Therapy is an international, peer-reviewed, open access journal focusing on the pathological basis of all cancers, potential targets for therapy and treatment protocols employed to improve the management of cancer patients. The journal also focuses on the impact of management programs and new therapeutic agents and protocols on

\section{Dovepress}

patient perspectives such as quality of life, adherence and satisfaction. The manuscript management system is completely online and includes a very quick and fair peer-review system, which is all easy to use. Visit http://www.dovepress.com/testimonials.php to read real quotes from published authors. 